\title{
Identificação botânica e química de espécies vegetais de uso popular no Rio Grande do Norte, Brasil
}

\author{
FÉLIX-SILVA, J.'; TOMAZ, I.M. ${ }^{1}$; SILVA, M.G. ${ }^{1}$; SANTOS, K.S.C.R. ${ }^{1}$; SILVA-JÚNIOR, A.A. ${ }^{1}$; CARVALHO, \\ M.C.R.D. ${ }^{1}$; SOARES, L.A.L. ${ }^{2}$; FERNANDES-PEDROSA, M.F. ${ }^{1 *}$ \\ ${ }^{1}$ Laboratório de Tecnologia \& Biotecnologia Farmacêutica (TecBioFar), Universidade Federal do Rio Grande do \\ Norte, CCS, Departamento de Farmácia, Avenida General Cordeiro de Farias, s/n, CEP: 59010-180, Natal-Brasil \\ *mpedrosa@ufrnet.br 2Laboratório de Farmacognosia, Universidade Federal de Pernambuco, CCS, Departamento \\ de Farmácia, Avenida Professor Arthur Sá, s/n, CEP: 50740-521, Recife-Brasil
}

\begin{abstract}
RESUMO: Plantas medicinais são utilizadas mundialmente como uma das principais formas de cuidado primário de saúde. No entanto, a literatura indica que muitas espécies podem apresentar composição química variável, toxicidade ou difícil identificação. O objetivo do presente estudo foi obter critérios úteis para o controle de qualidade farmacognóstico das principais espécies vegetais de uso popular no estado do Rio Grande do Norte, utilizando metodologias de análise botânica (morfodiagnose macro e microscópica) e química (triagem fitoquímica e cromatografia em camada delgada), evitando assim adulterações ou uso inadequado dessas plantas medicinais no estado. No total, sete espécies foram analisadas Acmella oleracea, Chenopodium ambrosioides, Lippia alba, Mentha piperita, Ocimum gratissimum, Peumus boldus e Rosmarinus officinalis. Diversos marcadores botânicos e fitoquímicos foram identificados, contribuindo dessa forma para a correta identificação destas espécies de plantas medicinais importantes no estado do Rio Grande do Norte.
\end{abstract}

Palavras-chave: plantas medicinais, Rio Grande do Norte, morfodiagnose, triagem fitoquímica, cromatografia em camada delgada (CCD)

\begin{abstract}
Botanical and chemical identification of plant species of popular use in Rio Grande do Norte, Brazil. Medicinal plants are worldwide used as one of the main forms of primary healthcare. However, the literature indicates that many species may have variable chemical composition, toxicity, or even difficult identification. The aim of this study was to obtain useful criteria for pharmacognostic quality control of the main plant species of popular use in the state of Rio Grande do Norte, using methods of botanical (macro and microscopic morphodiagnosis) and chemical (phytochemical screening and thin-layer chromatography) analysis, thus preventing adulteration or inappropriate use of these medicinal plants in the state. In total, seven species were analyzed Acmella oleracea, Chenopodium ambrosioides, Lippia alba, Mentha piperita, Ocimum gratissimum, Peumus boldus and Rosmarinus officinalis. Several botanical and phytochemical markers were identified, thereby contributing to the correct identification of these important medicinal plant species in the state of Rio Grande do Norte.
\end{abstract}

Key words: medicinal plants, Rio Grande do Norte, morphodiagnosis, phytochemical screening, thin-layer chromatography (TLC)

\section{INTRODUÇÃO}

O uso de plantas medicinais no tratamento de doenças é tão antigo quanto o próprio homem (Maciel et al., 2002). No Brasil, pesquisas demonstram que $82 \%$ da população brasileira utilizam produtos à base de espécies vegetais (Yunes et al., 2001). No entanto, essa prática pode se tornar bastante perigosa quando realizada sem orientação, pois muitas plantas podem apresentar difícil identificação, composição química variável ou ainda relativa toxicidade (Oliveira \& Akisue, 1997; Simões et al., 2007). Os nomes populares das plantas variam muito nas diferentes regiões do país, bem como um mesmo nome pode indicar diversas espécies diferentes, o que pode se transformar em sério fator de erro no uso de plantas medicinais (Oliveira \& Akisue, 1997). Dessa forma, análises botânicas e

Recebido para publicação em 25/01/2011

Aceito para publicação em 04/04/2012

Rev. Bras. PI. Med., Botucatu, v.14, n.3, p.548-555, 2012. 
químicas de espécies vegetais são de suma importância para a identificação e controle de qualidade farmacognóstico de plantas medicinais (Simões et al., 2007; Farmacopeia Brasileira, 2010a).

O presente estudo visou a obtenção de critérios úteis para o controle de qualidade farmacognóstico das principais espécies vegetais de uso popular no estado do Rio Grande do Norte (Brasil), utilizando metodologias de análise botânica (morfodiagnose macro e microscópica) e química (triagem fitoquímica e cromatografia em camada delgada), possibilitando, assim, evitar os casos de adulterações ou uso inadequado por conta de erros na identificação dessas plantas medicinais no estado. No total, foram analisadas botânica e quimicamente sete espécies, Acmella oleracea (L.) R. K. Jansen (Asteraceae), Chenopodium ambrosioides L. (Chenopodiaceae), Lippia alba (Mill.) N. E. Brown (Verbenaceae), Mentha piperita L. (Lamiaceae), Ocimum gratissimum L. (Lamiaceae), Peumus boldus Mol. (Monimiaceae) e Rosmarinus officinalis L. (Lamiaceae). Todas são espécies bastante conhecidas e difundidas no Brasil e, sobretudo, no Nordeste brasileiro, sendo comumente utilizadas no estado, principalmente, na forma de chás (infusos e decoctos) (Di Stasi \& Hiruma-Lima, 2002; Agra et al., 2008).

Acmella olarecea, conhecida popularmente por agrião ou jambu, é conhecida devido a propriedade analgésica, principalmente dos capítulos florais (Armond, 2007; Malosso, 2007). Chenopodium ambrosioides, conhecida como mastruz, é utilizada devido às propriedades antireumática, digestiva, antipirética, antimicrobiana, antifúngica, vermífuga, antiulcerogênica e cicatrizante (Di Istasi \& HirumaLima, 2002; Costa \& Tavares, 2006). Lippia alba, conhecida como erva-cidreira, tem uso popular devido as propriedades sedativa, antiespasmódica, analgésica, antitérmica, anti-inflamatória e emenagoga (Aguiar et al., 2008). Mentha piperita, conhecida como hortelã, tem uso medicinal pelas propriedades analgésica, antiemética, antiespasmódica, anti-inflamatória, antimicrobiana, antiviral, descongestionante e expectorante (Scavroni et al., 2006). Ocimum gratissimum, planta conhecida popularmente como alfavaca, possui propriedades antifúngica, antibacteriana, antidiarréica, analgésica, anestésica, antiagregrante, anti-séptica, hipoglicemiante e anti-inflamatória (Costa Filho et al., 2006). Peumus boldus, conhecido como boldo, é utilizado para o tratamento de distúrbios hepáticos e colelitíase, tendo ainda propriedades diuréticas, estomáquicas e antiinflamatórias (Ruiz et al., 2008). Rosmarinus officinalis, conhecido como alecrim, tem uso indicado como anti-inflamatório, analgésico, antitérmico, antiulcerativo, antiespasmódico, cicatrizante e carminativo (Al-Sereita et al., 1999).

\section{MATERIAL E MÉTODO}

\section{Amostras}

As sete espécies vegetais (Acmella oleracea, Chenopodium ambrosioides, Lippia alba, Mentha piperita, Ocimum gratissimum, Peumus boldus e Rosmarinus offiicinalis) foram selecionadas a partir de levantamento das plantas mais utilizadas em diferentes comunidades do estado. Dessas espécies, foram coletadas amostras frescas para posterior análise botânica e química.

\section{Análise botânica (morfodiagnose)}

Primeiramente, parte das amostras coletadas foi herborizada (prensada e seca, obtendo-se assim exsicatas) para identificação pela Dra Iracema Loyola (Herbário "Parque das Dunas" do Centro de Biociências da UFRN).

Partindo-se de amostras frescas, foi realizada a morfodiagnose macroscópica das folhas, na qual as amostras foram analisadas a olho nu observando-se a morfologia foliar conforme as características citadas por Oliveira \& Akisue (1997), tais como composição e estrutura foliar, nervação, filotaxia e formato da base, do ápice e da margem foliar.

Em seguida, a morfodiagnose microscópica foi desenvolvida utilizando-se amostras de folhas na forma de pó, obtido após secagem, trituração e tamisação (em malha de $0,42 \mathrm{~mm}$ ) do material vegetal. As lâminas foram preparadas com pequena quantidade do pó obtido juntamente com algumas gotas de cloral hidratado a 60\% (agente clareador). Estruturas importantes para a diagnose como tricomas, estômatos e inclusões foram analisadas e, quando aplicável, medidas (Alice et al., 1995; Oliveira \& Akisue, 1997; Arai \& Duarte, 2010).

\section{Análise química qualitativa}

Após a análise botânica, foi realizada a pesquisa dos compostos químicos presentes em cada espécie por meio de triagem fitoquímica e cromatografia em camada delgada (CCD). Para essas análises, foram preparados extratos aquosos a $10 \%$ (material vegetal: água, $\mathrm{p} / \mathrm{v}$ ) por decocção das folhas dessecadas e pulverizadas de cada planta (Simões et al., 2007).

A triagem fitoquímica foi realizada submetendo-se cada extrato a diversos testes qualitativos de precipitação e coloração específicos para as principais classes de metabólitos secundários, conforme Matos (1995) e Simões et al. (2007). Foram utilizadas reações específicas para a pesquisa de saponinas, taninos, gomas, mucilagens, flavonóides, heterosídeos senevólicos, quinonas, cumarinas, lactonas, fenóis, triterpenóides, carotenóides, alcalóides, catequinas e resinas.

$\mathrm{Na}$ cromatografia em camada delgada (CCD), 
foi investigada a presença de quercetina, ácido tânico, ácido gálico e catequina. Utilizou-se como fase estacionária cromatofolhas de sílica gel $60 \mathrm{~F}_{254} \mathrm{e}$ como fase móvel acetato de etila: acetona: ácido acético: água (6:2:1:1, v/v), sendo as placas reveladas com reagente natural $\mathrm{A}$ (2-aminoetildifenilborato $1 \%$ em metanol) e luz ultravioleta $365 \mathrm{~nm}$ (Lionço et al., 2001; Simões et al., 2007).

\section{RESULTADO E DISCUSSÃO}

\section{Análise botânica (morfodiagnose)}

Os resultados experimentais da morfodiagnose macro e microscópica, apresentados nas Tabelas 1 e 2 e na Figura 1, corroboram com os dados reportados na literatura para as espécies vegetais analisadas, tanto macro quanto microscopicamente, confirmando a identidade das mesmas.

A literatura botânica indica que as folhas de
Acmella oleracea são opostas, pecioladas, possuindo limbo com formato variando de oval a deltóide, base truncada, ápice agudo e com presença de pelos esparsos sobre ambas as faces superior e inferior (Hind \& Biggs, 2003).

Costa \& Tavares (2006) mostraram que a presença de tricomas tectores falciformes e glandulares vesiculosos e a presença de cristais de areia em células de bainha de feixe são caracteres úteis para a identificação da espécie Chenopodium ambrosioides. Além disso, esse estudo também identificou que a lâmina foliar é simétrica, tem forma oval, com ápice e base agudos, margem revoluta e pecíolo alado. Tricomas tectores multicelulares unisseriados com a célula basal arredondada e a terminal alongada com a forma de foice e tricomas glandulares vesiculosos também foram identificados por esses autores (Costa \& Tavares, 2006).

Dados da literatura indicam que Lippia alba

TABELA 1. Morfodiagnose macroscópica das folhas das espécies vegetais estudadas.

\begin{tabular}{|c|c|}
\hline Espécie vegetal analisada & Marcadores botânicos identificados \\
\hline $\begin{array}{l}\text { Acmella oleracea (L.) R.K. } \\
\text { Jansen (agrião) }\end{array}$ & $\begin{array}{l}\text { Folhas simples, opostas, } 5,5-10,5 \mathrm{~cm} \text { de comprimento por } 4,0-7,9 \mathrm{~cm} \text { de largura, } \\
\text { curtamente pecioladas, limbo oval, base simétrica e truncada, ápice agudo, margem } \\
\text { sinuosa, nervação peninérvea, folhas concolores, consistência membranácea, } \\
\text { superfície pubescente e ondulada, pecíolo lateral e de aspecto achatado. }\end{array}$ \\
\hline $\begin{array}{l}\text { Chenopodium } \\
\text { ambrosioides L. } \\
\text { (mastruz) }\end{array}$ & $\begin{array}{l}\text { Folhas simples, alternas, com } 8,0-9,9 \mathrm{~cm} \text { de comprimento por } 1,7-2,3 \mathrm{~cm} \text { de largura, } \\
\text { curtamente pecioladas, limbo alongado, lanceolado ou oval-alongado, base simétrica } \\
\text { e atenuada, ápice agudo, margem denteada, nervação peninérvea, folhas concolores, } \\
\text { consistência papirácea e pecíolo alado. }\end{array}$ \\
\hline $\begin{array}{l}\text { Lippia alba (Mill.) } \\
\text { N.E. Brown } \\
\text { (erva-cidreira) }\end{array}$ & $\begin{array}{l}\text { Folhas simples, opostas ou alternas, com 5,0-7,0 cm de comprimento por 3,1-5,2 cm } \\
\text { de largura, curtamente pecioladas, limbo oval, base cuneada e decurrente, ápice agudo, } \\
\text { margem serrilhada, nervação peninérvea, consistência membranácea, superfície } \\
\text { pubescente e pecíolo lateral. }\end{array}$ \\
\hline $\begin{array}{l}\text { Mentha piperita L. } \\
\text { (hortelã) }\end{array}$ & $\begin{array}{l}\text { Folhas simples, opostas, com 3,3-9,2 cm de comprimento por 1,3-5,1 cm de largura, } \\
\text { curtamente pecioladas, limbo oval, base assimétrica e arredondada, ápice agudo, } \\
\text { margem serrilhada, nervação peninérvea, consistência membranácea, superfície } \\
\text { rugosa e pecíolo canaletado. }\end{array}$ \\
\hline $\begin{array}{l}\text { Ocimum gratissimum L. } \\
\text { (alfavaca) }\end{array}$ & $\begin{array}{l}\text { Folhas simples, alternas, com 4,3-8,1 cm de comprimento por } 3,4-5,3 \mathrm{~cm} \text { de largura, } \\
\text { curtamente pecioladas, limbo óvalo-elíptico, base simétrica e atenuada, ápice } \\
\text { acuminado, margem denteada, nervação peninérvea e pecíolo lateral. }\end{array}$ \\
\hline $\begin{array}{l}\text { Peumus boldus Mol. } \\
\text { (boldo) }\end{array}$ & $\begin{array}{l}\text { Folhas simples, opostas, com 4,5-6,0 cm de comprimento por } 2,1-5,1 \mathrm{~cm} \text { de largura, } \\
\text { curtamente pecioladas, limbo óvalo-elíptico, base simétrica e arredondada, ápice obtuso, } \\
\text { margem revoluta, nervação peninérvea, consistência coriácea e superfície áspera e } \\
\text { pecíolo lateral. A folha, quando observada contra a luz, mostra pontuações translúcidas. }\end{array}$ \\
\hline $\begin{array}{l}\text { Rosmarinus officinalis L. } \\
\text { (alecrim) }\end{array}$ & $\begin{array}{l}\text { Folhas simples, opostas, com 2,0-5,3 cm de comprimento por } 1,0-2,5 \mathrm{~cm} \text { de largura, } \\
\text { sésseis, limbo lanceolado, base simétrica, ápice obtuso, margem inteira e revoluta, } \\
\text { nervação uninérvea, superfície rugosa e luzidia e folhas discolores, apresentando a } \\
\text { face adaxial coloração esverdeada, aspecto rugoso e brilhante enquanto que a face } \\
\text { abaxial apresentou-se esbranquiçada. }\end{array}$ \\
\hline
\end{tabular}

Rev. Bras. PI. Med., Botucatu, v.14, n.3, p.548-555, 2012. 
se caracteriza por folhas opostas ou alternas ovais ou óvalo-oblongas, curtamente pecioladas, com margem serreada, com superfície de aspecto rugoso e com nervuras marcadamente proeminentes (Tavares, 2009). É descrita a presença de quatro tipos de tricomas, um tector (com ápice agudo e base elevada por células epidérmicas) e três glandulares. Segundo a literatura, os tricomas glandulares sésseis estão presentes na face abaxial formado por célula basal, intermediária e porção capitada bicelular e os dois últimos tipos encontram-se distribuídos em ambas as faces foliares (Alice et al., 1995; Barros, 2008).

Segundo a Farmacopéia Brasileira (2010b), as folhas de Mentha piperita são caracterizadas por serem membranosas, rugosas, quebradiças, opostas e curtamente pecioladas, além de apresentarem limbo oval, ápice agudo, base irregularmente arredondada e assimétrica, e margem irregularmente serrilhada. Na literatura é indicada a ocorrência de cinco tipos de tricomas: tricoma tector pluricelular, longo, delgado, agudo, unisseriado, podendo possuir coroa de células basais; tricoma tector pluricelular com duas a seis células, bisseriado na base, com cutícula espessa e estriada; tricoma glandular com pedicelo unicelular curto e cabeça unicelular arredondada, com cutícula delgada; tricoma glandular com pedicelo unicelular, bicelular ou tricelular curto e cabeça unicelular elíptica, com cutícula delgada; e tricoma glandular peltado, de pedicelo curto, formado por uma ou duas células na porção basal e cabeça pluricelular com oito células de disposição radial.

Estudos com dados botânicos da espécie Ocimum gratissimum são relativamente escassos. Análises da anatomia foliar da espécie já realizados indicam que a mesma caracteriza-se por apresentar tricomas tectores pluricelulares e tricomas glandulares captados e peltados na face adaxial e abaxial (Martins et al., 2009).

Peumus boldus, conforme a Farmacopeia Brasileira (2010b), é uma espécie composta de folhas simples, com formato variando de elíptico, oval, elíptico oboval ou oboval, de ápice obtuso, retuso ou agudo e base arredondada, obtusa ou cuneada. Tem como característica marcante a presença de pontuações levemente translúcidas, correspondentes

TABELA 2. Morfodiagnose microscópica das folhas das espécies vegetais estudadas.

Espécie vegetal analisada Marcadores microscópicos identificados

Acmella oleracea (L.)

R. K. Jansen (agrião)

Tricomas tectores unicelulares de formato acicular medindo entre 208-260 $\mu \mathrm{m}$ e tricomas tricelulares abundantes medindo entre 227,5-357,5 $\mu \mathrm{m}$, epiderme com células com formato irregular e contorno sinuoso em forma de quebra-cabeça ("jogo de encaixe"), estômatos com células reniformes e parênquima repleto de glândulas de óleo essencial.

Chenopodium ambrosioides L. (mastruz)
Tricomas tectores de formato acicular, unisseriados, constituído por duas células, sendo a célula basal colabada, medindo entre 162,5-195 $\mu \mathrm{m}$; tricomas tectores de formato acicular, unisseriados, constituído por três células, sendo a célula mediana levemente colabada; tricomas tectores constituídos de três células, sendo a célula basal arredondada; tricomas tectores unicelulares com formato de dedo de luva com tamanho variando entre 130-227,5 $\mu \mathrm{m}$; epiderme mostrando células poliédricas com contorno reto ou ligeiramente sinuoso.

Lippia alba (Mill.) N.E. Brown (erva-cidreira)

Tricomas tectores, unicelulares e aciculares, epiderme inferior e superior com células em forma de "jogo de encaixe" com margens onduladas.

Mentha piperita L. (hortelã)
Grande número de tricomas, incluindo tricomas tectores de formato acicular, unisseriado, constituído por quatro células, nos quais a célula basal é um pouco dilatada e a célula sobre a célula basal é ligeiramente colabada; tricomas glandulares medindo $338 \mu \mathrm{m}$; marcante presença de tricomas tectores com base em forma de cálice medindo entre 403$598 \mu \mathrm{m}$.

\begin{tabular}{ll}
\hline $\begin{array}{l}\text { Ocimum gratissimum } \mathrm{L} . \\
\text { (alfavaca) }\end{array}$ & $\begin{array}{l}\text { Tricomas tectores pluricelulares aciculares e epiderme inferior com células em forma de } \\
\text { "jogo de encaixe". }\end{array}$ \\
\hline $\begin{array}{l}\text { Peumus boldus Mol. } \\
\text { (boldo) }\end{array}$ & $\begin{array}{l}\text { Tricomas tectores em forma de estrela com tamanho variando entre } 36-277 \mu \mathrm{m} \text { e tricomas } \\
\text { isolados de } 57,6-252 \mu \mathrm{m} \text { e epiderme superior com células de contorno reto. }\end{array}$ \\
\hline $\begin{array}{l}\text { Rosmarinus } \\
\text { officinalis } \mathrm{L} .\end{array}$ & $\begin{array}{l}\text { Tricomas tectores em forma de estrela, medindo entre } 54-111,6 \mu \mathrm{m} \text { de comprimento, } \\
\text { (alecrim) }\end{array}$ \\
\hline
\end{tabular}

Rev. Bras. PI. Med., Botucatu, v.14, n.3, p.548-555, 2012. 


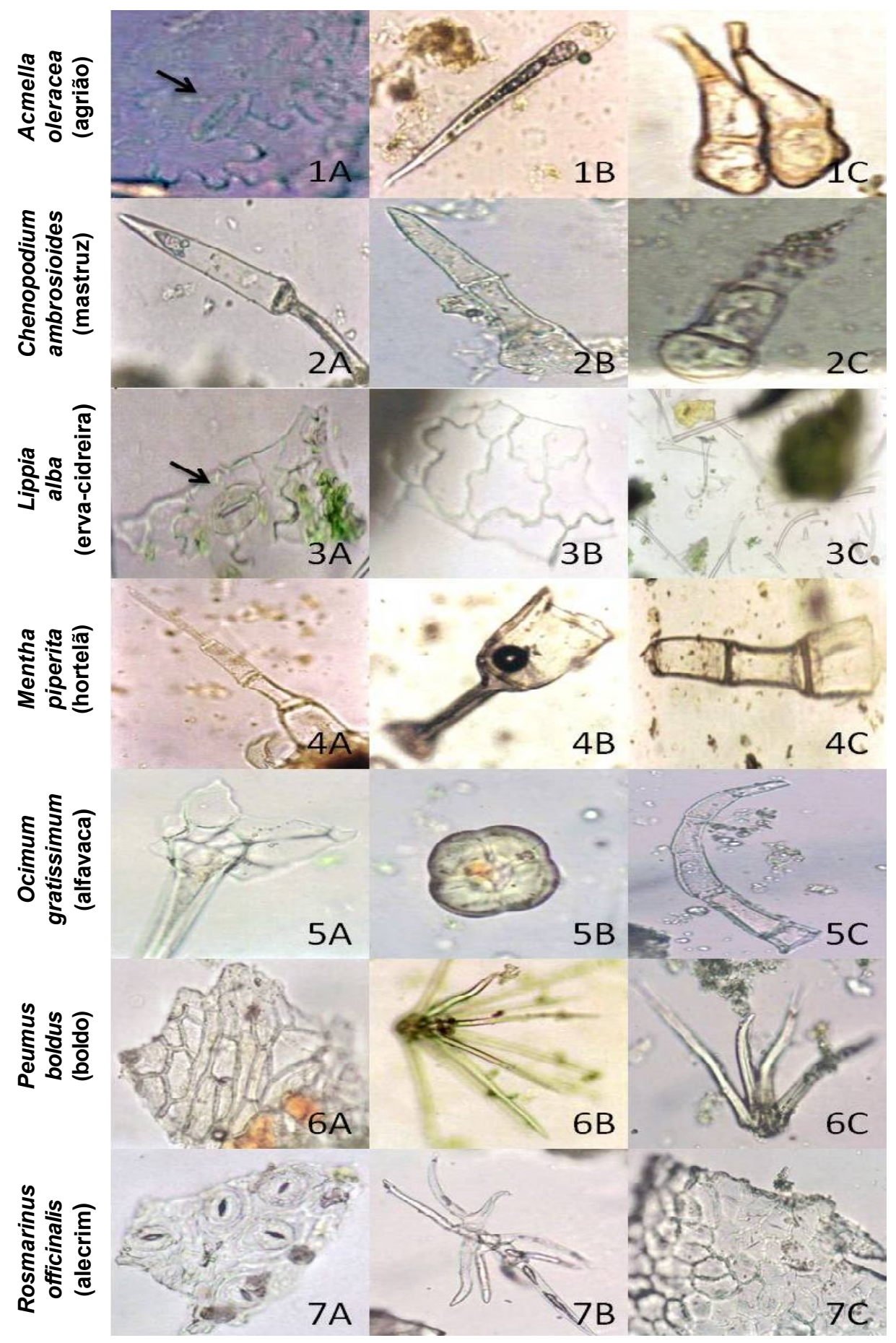

FIGURA 1. Morfodiagnose microscópica do pó das folhas das espécies vegetais em estudo. 1- Acmella oleracea (Afragmento de epiderme inferior com células em "jogo de encaixe" e estômato com células reniformes; B- tricoma tector unicelular acicular; C- tricomas tectores aciculares), 2- Chenopodium ambrosioides (A- tricoma tector acicular unisseriado dicelular com célula basal colabada; B- tricoma tector acicular unisseriado tricelular com célula mediana levemente colabada; C- tricoma tector tricelular com célula basal arredondada), 3- Lippia alba (A- fragmento de epiderme inferior com células em "jogo de encaixe" e estômato com células reniformes; B- fragmento de epiderme superior com células em forma de "jogo de encaixe" com margens onduladas; C- fragmentos de tricomas unicelulares aciculares tectores), 4Mentha piperita (A- tricoma tector acicular unisseriado constituído por quatro células, com célula basal levemente dilatada e célula posterior à basal ligeiramente colabada; B- base de tricoma tector em forma de cálice; C- tricoma tector acicular unisseriado pluricelular), 5- Ocimum gratissimum (A- base de tricoma tector; B- base de tricoma glandular; Ctricoma tector acicular pluricelular); 6- Peumus boldus (A- fragmento de epiderme superior com células de contorno reto; $B-$ tricoma tector estrelado apresentando numerosos ramos; C- tricoma tector estrelado apresentando quatro ramos); 7Rosmarinus officinalis (A- fragmento de epiderme inferior com estômatos; B- tricoma tector ramificado; C- fragmento de epiderme superior com células de contorno reto). 
a cavidades secretoras, visíveis a olho nu ou com lente de aumento de seis vezes.

Estudos botânicos de Rosmarinus officinalis também são relativamente escassos. Marin et al. (2006), num estudo dos tricomas glandulares presentes nas folhas desta espécie, constataram que as folhas apresentam tanto tricomas tectores como glandulares em ambas as faces da lâmina foliar. Tricomas glandulares estão presentes nas nervuras e nas margens foliares. Além disso, foram encontrados alguns tricomas tectores unicelulares e numerosos tricomas multicelulares e ramificados (Marin et al., 2006).

\section{Análise química qualitativa}

A partir da triagem fitoquímica dos extratos das folhas foi identificada a presença das principais classes de metabólitos secundários presentes nessas espécies (Tabela 3). Na CCD foi pesquisada a presença de ácido gálico, ácido tânico, catequina e quercetina, devido à notada presença de fenóis em todas as espécies na triagem fitoquímica. Nos extratos de Peumus boldus foram identificadas manchas indicativas da presença de catequina e quercetina. No extrato de Lippia alba identificou-se ácido tânico e no de Rosmarinus officinalis foi observada a presença de catequina. Para as demais espécies, não foi identificada a presença dos padrões utilizados (Tabela 3).
A partir das análises fitoquímicas, puderam ser identificados os principais grupos de substâncias já referidos na literatura para essas espécies.

Embora grande parte dos estudos da composição química de Lippia alba estejam relacionados aos seus óleos voláteis, alguns trabalhos reportam a presença de taninos, flavonóides, saponinas e esteróides em extratos da planta (Corrêa, 2005). Estudos fitoquímicos com extratos aquosos de Ocimum gratissimum indicam a presença de saponinas, taninos, antraquinonas, esteróides, terpenóides, flavonóides e glicosídeos cardiotônicos (Akinmoladun et al., 2007). Peumus boldus tem como principal classe de constituintes os alcalóides, dentre os quais o principal é a boldina (Farmacopeia Brasileira, 2010b), sendo também reportadas na espécie a presença de fenóis, taninos, flavonóides e catequinas (Melo et al., 2004).

Estudos fitoquímicos sistemáticos das folhas das espécies Acmella oleracea, Chenopodium ambrosioides, Mentha piperita e Rosmarinus officinalis são escassos na literatura, o que limita a quantidade de dados referenciais para comparação. Grande parte dos estudos químicos com as espécies Chenopodium ambrosioides, Mentha piperita e Rosmarinus officinalis está relacionada à composição de seus óleos voláteis (Fecka et al., 2004; Farmacopeia Brasileira, 2010b). No entanto, alguns trabalhos reportam para essas quatro espécies a

TABELA 3. Metabólitos secundários identificados no extrato aquoso das folhas das plantas estudadas.

\begin{tabular}{|c|c|c|}
\hline Espécie vegetal analisada & $\begin{array}{l}\text { Classes de metabólitos secundários } \\
\text { encontrados na triagem fitoquímica }\end{array}$ & Fenóis identificados pela CCD \\
\hline $\begin{array}{l}\text { Acmella oleracea (L.) R.K. } \\
\text { Jansen (agrião) }\end{array}$ & $\begin{array}{l}\text { Taninos, gomas, cumarinas, fenóis e } \\
\text { alcalóides }\end{array}$ & $\begin{array}{l}\text { Nenhum dos fenóis pesquisados } \\
\text { foi identificado }\end{array}$ \\
\hline $\begin{array}{l}\text { Chenopodium ambrosioides L. } \\
\text { (mastruz) }\end{array}$ & $\begin{array}{l}\text { Taninos, gomas, heterosídeos senevólicos, } \\
\text { mucilagens, cumarinas, fenóis, esteróides, } \\
\text { triterpenóides, carotenóides e alcalóides }\end{array}$ & $\begin{array}{l}\text { Nenhum dos fenóis pesquisados } \\
\text { foi identificado }\end{array}$ \\
\hline $\begin{array}{l}\text { Lippia alba (Mill.) N. E. Brown } \\
\text { (erva-cidreira) }\end{array}$ & $\begin{array}{l}\text { Taninos, gomas, saponinas, fenóis, lactonas, } \\
\text { cumarinas, catequinas, resinas e alcalóides }\end{array}$ & Ácido tânico \\
\hline Mentha piperita L. (hortelã) & $\begin{array}{l}\text { Taninos, gomas, heterosideos senevólicos, } \\
\text { cumarinas, fenóis, esteróides, triterpenóides, } \\
\text { carotenóides, resinas e alcalóides }\end{array}$ & $\begin{array}{l}\text { Nenhum dos fenóis pesquisados } \\
\text { foi identificado }\end{array}$ \\
\hline $\begin{array}{l}\text { Ocimum gratissimum L. } \\
\text { (alfavaca) }\end{array}$ & $\begin{array}{l}\text { Taninos, gomas, fenóis, saponinas, lactonas, } \\
\text { cumarinas e resinas }\end{array}$ & $\begin{array}{l}\text { Nenhum dos fenóis pesquisados } \\
\text { foi identificado }\end{array}$ \\
\hline Peumus boldus Mol. (boldo) & $\begin{array}{l}\text { Taninos, gomas, fenóis, saponinas, } \\
\text { catequinas, resinas e alcalóides }\end{array}$ & Catequina e quercetina \\
\hline $\begin{array}{l}\text { Rosmarinus officinalis L. } \\
\text { (alecrim) }\end{array}$ & $\begin{array}{l}\text { Taninos, gomas, fenóis, saponinas, lactonas } \\
\text { e resinas }\end{array}$ & Catequina \\
\hline
\end{tabular}


presença de fenóis de um modo geral (Al-Sereita et al., 1999; Fecka et al., 2004; Cruz et al., 2007; Malosso, 2007).

\section{CONCLUSÃO}

Os resultados das análises botânicas e químicas das plantas Acmella oleracea, Chenopodium ambrosioides, Lippia alba, Mentha piperita, Ocimum gratissimum, Peumus boldus e Rosmarinus officinalis permitiram estabelecer parâmetros úteis para a confirmação da autenticidade dessas espécies vegetais. Quando os resultados aqui obtidos foram confrontados com os dados da literatura, observou-se que houve concordância entre eles, comprovando a adequada identificação das espécies. No entanto, para algumas plantas, a literatura é relativamente escassa, principalmente em relação aos dados fitoquímicos, dificultando assim um estudo comparativo. Dessa forma, este trabalho contribui para um melhor controle farmacognóstico dessas espécies, evitando assim casos de adulteração ou uso inadequado dessas plantas medicinais importantes no Nordeste brasileiro, especialmente no estado do Rio Grande do Norte.

\section{AGRADECIMENTO}

Os autores agradecem à professora M. Sc. Maria Célia Aguiar (Departamento de Farmácia UFRN), à farmacêutica Maria Aparecida do Nascimento (Departamento de Análises Clínicas e Toxicológicas - UFRN) e aos alunos de graduação em Farmácia da UFRN, Anassely Bessa, Ítalo Veríssimo, Jacyra Antunes e Micaelly Moura, pelo fundamental auxílio nas análises fitoquímicas.

\section{REFERÊNCIA}

AGUIAR, J.S. et al. Atividade antimicrobiana de Lippia alba (Mill.) N. E. Brown (Verbenaceae). Revista Brasileira de Farmacognosia, v.18, n.3, p.436-40, 2008.

AGRA, M.F. et al. Survey of medicinal plants used in the region Northeast of Brazil. Revista Brasileira de Farmacognosia, v.18, n.3, p.472-508, 2008.

AKINMOLADUN, A.C. et al. Phytochemical constituent and antioxidant activity of extract from the leaves of Ocimum gratissimum. Scientific Research and Essays, v.2, n.5, p.163-6, 2007.

ALICE, C.B. et al. Plantas medicinais de uso popular: atlas farmacognóstico. Canoas: Ulbra, 1995. 205p. AL-SEREITA, M.R.; ABU-AMERB, K.M.; SENA, P. Pharmacology of rosemary (Rosmarinus officinalis Linn.) and its therapeutic potentials. Indian Journal of Experimental Biology, v.37, p.124-31, 1999.

ARAI, M.; DUARTE, S.G. Tricomas fósseis como nova categoria de palinomorfos lato sensu: sua classificação preliminar e aplicabilidade na Bioestratigrafia. Boletim do Museu Paraense Emílio Goeldi, v.5, n.2, p.175-88, 2010.

ARMOND, C. Indicadores químicos, crescimento e bioeletrografias de plantas de jambu (Acmella oleracea L.), capim-limão (Cymbopogon citratus (DC.) Stapf.) e folha-da-fortuna (Bryophyllum pinnatum (Lam.) Oken) submetidas a tratamentos homeopáticos. 2007. 142p. Tese (Doutorado em Ciências) - Universidade Federal de Viçosa, Viçosa.

BARROS, F.M.C. Variabilidade sazonal, atividade antimicrobiana, fracionamento bio-guiado, isolamento e elucidação estrutural dos principais constituintes do óleo essencial de Lippia alba (Mill.) N. E. Brown. 2008. 161p. Dissertação (Mestrado - Área de Concentração em Controle e Avaliação de Insumos e Produtos Farmacêuticos) - Universidade Federal de Santa Maria, Santa Maria.

CORREAA, M.M. Estudo fitoquímico da fração $n$ butanólica de Lippia alba (Mill.) N.E. Br. 2005. 117p. Dissertação (Mestrado em Farmácia) - Universidade Federal de Santa Catarina, Florianópolis.

COSTA, M.V.L.; TAVARES, E.S. Anatomia foliar de Chenopodium ambrosioides L. (Chenopodiaceae) Erva-de-Santa Maria. Revista Brasileira de Plantas Medicinais, v.8, n.3, p.63-71, 2006.

COSTA FILHO, L.O.; ENCARNAÇÃO, C.R.F.; OLIVEIRA, A.F.M. Influência hídrica e térmica no crescimento e desenvolvimento de Ocimum gratissimum L. Revista Brasileira de Plantas Medicinais, v.8, n.2, p.8-13, 2006. CRUZ, G.V.B. et al. Increase of cellular recruitment, phagocytosis ability and nitric oxide production induced by hydroalcoholic extract from Chenopodium ambrosioides leaves. Journal of Ethnopharmacology, v.111, p.148-54, 2007.

DI STASI, L.C.; HIRUMA-LIMA, C.A. Plantas medicinais na Amazônia e na Mata Atlântica. 2.ed. São Paulo: UNESP, 2002. 604p.

FARMACOPEIA BRASILEIRA, 5.ed. Volume I. Brasília: Anvisa, 2010a. 546p.

FARMACOPEIA BRASILEIRA, 5.ed. Volume II. Brasília: Anvisa, 2010b. 836p.

FECKA, I. et al. Optimization of the separation of flavonoid glycosides and rosmarinic acid from Menha piperita on HPTLC plates. Journal of Planar Chromatography, v.17, n.1, p.22-5, 2004.

HIND, N.; BIGGS, N. Acmella oleracea: Compositae. Curtis's Botanical Magazine, v.20, n.1, p.31-9, 2003.

LIONÇO, M.I.; SOUZA, T.P.; PETROVICK, P.R. Avaliação cromatográfica de polifenóis presentes nas partes morfológicas de Phyllanthus niruri. Caderno de Farmácia, v.17, n.2, p.117-20, 2001.

MACIEL, M.A.M. et al. Plantas medicinais: a necessidade de estudos multidisciplinares. Química Nova, v.25, n.3, p.429-38, 2002.

MALOSSO, M.G. Micropropagação de Acmella oleracea (L.) R. K. Jansen e estabelecimento de meio de cultura para a conservação desta espécie em banco de germoplasma in vitro. 2007. 90p. Tese (Doutorado Área de Concentração Agroflorestal) - Universidade Federal do Amazonas, Coari.

MARIN, M. et al. Glandular trichomes on the leaves of Rosmarinus officinalis: morphology, stereology and

Rev. Bras. PI. Med., Botucatu, v.14, n.3, p.548-555, 2012. 
histochemistry. South African Journal of Botany, v.72, p.378-82, 2006.

MARTINS, J.R. et al. Anatomia foliar de plantas de alfavaca-cravo cultivadas sob malhas coloridas. Ciência Rural, v.39, n.1, p.82-7, 2009.

MATOS, F.J.A. Introdução a fitoquímica experimental. Fortaleza: EUFC, 1995. 123p.

MELO, J.G. et al. Avaliação da qualidade de amostras comerciais de boldo (Peumus boldus Molina), pata-devaca (Bauhinia spp.) e ginco (Ginkgo biloba L.). Revista Brasileira de Farmacognosia, v.14, n.2, p.111-20, 2004. OLIVEIRA, F.; AKISUE, G. Fundamentos de farmacobotânica. 2.ed. São Paulo: Atheneu, 1997. 178p.

RUIZ, A.L.T.G. et al. Farmacologia e toxicologia de Peumus boldus e Baccharis genistelloides. Revista Brasileira de Farmacognosia, v.18, n.2, p.295-300, 2008. SCAVRONI, J. et al. Rendimento e composição química do óleo essencial de Mentha piperita L. submetida a aplicações de giberelina e citocinina. Revista Brasileira de Plantas Medicinais, v.8, n.4, p.40-3, 2006.

SIMÕES, C.M.O. et al. (Orgs.). Farmacognosia: da planta ao medicamento. 6.ed. revisada e ampliada. Porto Alegre/Florianópolis: Editora da UFRGS/Editora da UFSC, 2007. 1102p.

TAVARES, I.B. Propagação vegetativa, adubação orgânica e idades de colheita de quimitipos de ervacidreira [Lippia alba (Mill.) N. E. Brown]. 2009. 84p. Dissertação (Mestrado em Produção Vegetal) Universidade Federal do Tocantins, Gurupi.

YUNES, R.A.; PEDROSA, R.C.; CECHINEL FILHO, V. Fármacos e fitoterápicos: a necessidade do desenvolvimento da indústria de fitoterápicos e fitofármacos no Brasil. Química Nova, v.24, n.1, p.147-52, 2001. 